\title{
One-way calcium spill-over during signal transduction in Paramecium cells: from the cell cortex into cilia, but not in the reverse direction
}

\author{
Marc R. Husser, Martin Hardt ${ }^{1}$, Marie-Pierre Blanchard ${ }^{2}$, \\ Joachim Hentschel, Norbert Klauke ${ }^{3}$, Helmut Plattner* \\ Department of Biology, University of Konstanz, P.O. Box 5560, 78457 Konstanz, Germany
}

Received 9 October 2003; received in revised form 23 January 2004; accepted 3 February 2004

\begin{abstract}
We asked to what extent $\mathrm{Ca}^{2+}$ signals in two different domains of Paramecium cells remain separated during different stimulations. Wild-type (7S) and pawn cells (strain $d 4-500 r$, without ciliary voltage-dependent $\mathrm{Ca}^{2+}$-channels) were stimulated for trichocyst exocytosis within $80 \mathrm{~ms}$ by quenched-flow preparation and analysed by energy-dispersive X-ray microanalysis (EDX), paralleled by fast confocal fluorochrome analysis. We also analysed depolarisation-dependent calcium signalling during ciliary beat rerversal, also by EDX, after 80-ms stimulation in the quenched-flow mode. EDX and fluorochrome analysis enable to register total and free intracellular calcium concentrations, $[\mathrm{Ca}]$ and $\left[\mathrm{Ca}^{2+}\right]$, respectively. After exocytosis stimulation we find by both methods that the calcium signal sweeps into the basis of cilia, not only in $7 S$ but also in pawn cells which then also perform ciliary reversal. After depolarisation we see an increase of [Ca] along cilia selectively in $7 \mathrm{~S}$, but not in pawn cells. Opposite to exocytosis stimulation, during depolarisation no calcium spill-over into the nearby cytosol and no exocytosis occurs. In sum, we conclude that cilia must contain a very potent $\mathrm{Ca}^{2+}$ buffering system and that ciliary reversal induction, much more than exocytosis stimulation, involves strict microdomain regulation of $\mathrm{Ca}^{2+}$ signals. $^{2}$
\end{abstract}

Keywords: $\mathrm{Ca}^{2+}$; Calcium; Cilia; EDX; Paramecium; X-ray microanalysis

\section{Introduction}

$\mathrm{Ca}^{2+}$ is a pivotal second messenger in numerous cell functions [1-5], including stimulated secretory activity [2] and ciliary beat regulation [6-9]. This also holds true for ciliated protozoa [10-14]. In ciliates dense-core exocytotic vesicles and cilia exist side-by-side in regular intervals [15]. In Paramecium, the distance of these organelles is $\sim 1 \mu \mathrm{m}$, thus aggravating differential signal transduction [16]. In Paramecium, depolarisation-induced activation of ciliary $\mathrm{Ca}^{2+}$-channels causes ciliary beat reversal and backward

\footnotetext{
* Corresponding author. Tel.: +49-7531-88-2228; fax: +49-7531-88-2245.

E-mail address: helmut.plattner@uni-konstanz.de (H. Plattner).

${ }^{1}$ Present address: Justus-Liebig-Universität Giessen, Zentrale Biotechnische Betiebseinheit (ZBB) im Strahlenzentrum, Leihgesterner Weg 217, 35392 Giessen, Germany.

${ }^{2}$ Present address: INSERM U 432, Université de Montpellier 2, Place Eugène Bataillon, 34095 Monpellier, Cedex 05, France.

${ }^{3}$ Present address: Department of Electronics \& Electronical Engineering, Rankine Building, Oakfield Avenue, Glasgow GL12 8LT, Scotland, UK.
}

swimming, respectively $[10,11,13,17-20]$, with no exocytotic response [21]. These channels are irrelevant for exocytosis [22]. With permeabilised Paramecium cells, ciliary reversal is induced by a $\mathrm{Ca}^{2+}$ concentration of $10^{-6} \mathrm{M}$ [23]. In contrast, trichocyst exocytosis requires $\sim 5 \times 10^{-6} \mathrm{M}$ [24] and relies on two different $\mathrm{Ca}^{2+}$ sources, (i) $\mathrm{Ca}^{2+}$ from cortical stores ("alveolar sacs") and (ii) from superimposed store-operated $\mathrm{Ca}^{2+}$ influx (SOC) via the non-ciliary cell membrane [21,25-27]. A Paramecium cell is able to selectively activate either one of the two phenomena, evidently by microdomain $\mathrm{Ca}^{2+}$ regulation.

The differential activation of $\mathrm{Ca}^{2+}$-mediated processes is difficult to analyse with fluorochromes. Particularly, with cilia this is problematic $[8,28,29]$. Difficulties in determining precise free $\mathrm{Ca}^{2+}$ concentrations, $\left[\mathrm{Ca}^{2+}\right]$, within cilia and flagella have several reasons, not only the small size, but also unknown diffusion effects [30] after passing $\mathrm{Ca}^{2+}$-channels whose distribution along the cilium is unknown (see "Section 4"), as is that of a still increasing number of $\mathrm{Ca}^{2+}$-activated and $\mathrm{Ca}^{2+}$-binding proteins (CaBPs) [31-35], not to speak of practical problems with fluorochrome analyses in these slender and highly motile 
structures. Alternative methods, like intracellular application of $\mathrm{Ca}^{2+}$ chelators of different $k_{\mathrm{D}}$ or local photoactivation of caged $\mathrm{Ca}^{2+}$, as it is widely used in exocytosis research [36], proved useful merely on a rather coarse scale, at best to compare proximal and distal regions of cilia in Paramecium [37].

Recently, we have established with Paramecium cells energy-dispersive X-ray microanalysis (EDX) combined with scanning transmission electron microscopy (STEM) to determine local values of total calcium concentrations, [Ca], i.e. bound calcium and free $\mathrm{Ca}^{2+}[38,39]$. The preparative method we apply is quenched-flow/fast freezing [40] combined with freeze-substitution at $193 \mathrm{~K}$ in presence of fluoride as a calcium precipitating ion of very low solubility [38,41], based on previous work by Poenie and Epel [42]. The quenched-flow/cryofixation method we developed allows stimulation times in the sub-second range. For comparison, synchronous trichocyst exocytosis occurs within $80 \mathrm{~ms}$ [40], whereas one ciliary beat requires $\sim 50 \mathrm{~ms}$ (see "Section 3"). While we register considerable changes in Ca $\mathrm{K} \alpha$ EDX signals upon exocytosis stimulation [38,39], we find no evidence of any artificial redistribution during mock stimulation. Exocytosis stimulation involves depletion of cortical Ca stores (alveolar sacs) superimposed by a $\mathrm{Ca}^{2+}$ influx during exocytosis stimulation, i.e. a store-operated $\mathrm{Ca}^{2+}$ influx, SOC [39]—a mechanism basically different from that occurring in cilia. We use $500 \mathrm{~nm}$ sections and operate the STEM at a spot size of $63 \mathrm{~nm}$, with a calculated spread to $72 \mathrm{~nm}$ at the bottom, which thus reflects the resolution of $\mathrm{Ca} \mathrm{K} \alpha$ signal localisation by EDX whose sensitivity limit we have determined as [Ca] $\sim 2 \mathrm{mM}[39]$.

In the present paper, we analyse calcium in cilia by measuring both, $\left[\mathrm{Ca}^{2+}\right]$ by fluorochromes at the light microscope (LM) and [Ca] by EDX at the electron microscope (EM) level. While at $\mathrm{LM}$ resolution $\left[\mathrm{Ca}^{2+}\right]$ is difficult to determine in cilia, $[\mathrm{Ca}]$ values determined at the EM level after stimulation allow one to clearly trace calcium fluxes within fine subcellular details and eventual spill-over into nearby domains. This appears particularly promising for cilia because the arrangement of voltage-dependent $\mathrm{Ca}^{2+}$-channels is not known.

Our EDX analysis with wild-type (7S) cells reveals massive calcium fluxes into cilia, not only during depolarisation, but also during exocytosis stimulation. We also observe $\mathrm{Ca}^{2+}$ spill-over in the "tightest" pawn cells (devoid of the voltage-dependent $\mathrm{Ca}^{2+}$-channels in cilia), strain $d 4-500 r$ [43], into the basis in cilia, when exocytosis is stimulated. This causes ciliary reversal which these cells do not show under depolarisation conditions. We see no spill-over in the opposite direction, i.e. from the cilia into the cell soma when $7 S$ cells are depolarised. Possible explanations of this difference may be, for instance, not only different $\mathrm{Ca}^{2+}$-sensitivity, but also the magnitude of the respective calcium fluxes and signals, as well as different $\mathrm{Ca}^{2+}$ buffering capacity. Therefore, it was useful to monitor real calcium distributions by EDX.
As to possible biological implications in Paramecium, ciliary reversal rapidly ensues exocytosis during defence against a predator attack. Both these mechanisms acting in concert may explain their enormous efficiency of this defence mechanism [44].

\section{Materials and methods}

\subsection{Cell cultures and stimulation for EDX}

Cells, wild-type strain $7 S$ and pawn strain $d 4-500 r$ [43], were cultivated as described [24] and prepared by quenched-flow/freeze-substitution. Briefly, the methodology developed in our lab was used for quenched-flow [40] and for freeze-substitution under conditions allowing to retain $\mathrm{Ca}^{2+}[38,41]$. Depolarisation was performed in media with $\left[\mathrm{Ca}^{2+}\right]_{\mathrm{o}}=1.0 \mathrm{mM}$ by rapid mixing in the quenched-flow apparatus with $\mathrm{KCl}$, resulting in $\left[\mathrm{K}^{+}\right]_{\mathrm{o}}=20 \mathrm{mM}$. To analyse the effects of synchronous trichocyst exocytosis, cells were exposed to $2 \mu \mathrm{M}$ aminoethyldextran (AED), routinely at $\left[\mathrm{Ca}^{2+}\right]_{\mathrm{o}}=0.5 \mathrm{mM}[39]$.

\section{2. $E D X$}

This method was applied as described by Hardt and Plattner $[38,39]$. Briefly, semithin sections of $0.5 \mu \mathrm{m}$ were prepared and analysed in a LEO 912 Omega EM operated in the scanning transmission (STEM) mode at $80 \mathrm{kV}, \sim 10 \mu \mathrm{A}$ beam current, using a spot size of $63 \mathrm{~nm}$ (bottom $72 \mathrm{~nm}$ [38]) for spot measurements of $\mathrm{Ca} \mathrm{K} \alpha$ signals. Cilia were analysed along their shaft and signals were recorded also from other sites of the cell as indicated in figures and tables.

\subsection{Fluorochrome measurements}

Cells were loaded with Fluo- 3 and the $f / f_{\mathrm{o}}$ signal ratio during stimulation was analysed with a confocal laser scanning microscope (CLSM) type Tracor/Noran Odyssey, equipped with a fast opto-acustic deflection system, as described previously [24-26]. During stimulation, signals were recorded close to the site of stimulus application, not only in the cell cortex, but also in an extracellular area adjacent to the cell surface, i.e. in the layer containing beating cilia. The fields to be analysed were framed $(\sim 5 \mu \mathrm{m}$ wide parallel to the cell surface) and the signals recorded were processed as described [24-26].

\section{Results}

Table 1 summarises the effects of depolarisation in $7 S$ and $d 4-500 r$ cells. The ability and inability of $7 S$ and $d 4-500 r$ cells, respectively, was routinely tested immediately before quenched-flow preparation for subsequent EDX analysis. Under the depolarisation conditions used throughout this 
Table 1

Reaction of $7 S$ and $d 4-500 r$ cells to depolarisation conditions and to exocytosis stimulation, respectively ${ }^{\mathrm{a}}$

\begin{tabular}{|c|c|c|c|c|}
\hline & \multicolumn{2}{|c|}{ Ciliary reversal (depolarisation) } & \multicolumn{2}{|c|}{ Exocytosis (AED stimulation) } \\
\hline & $7 S$ & $d 4-500 r$ & $7 S$ & $d 4-500 r$ \\
\hline $20 \mathrm{mM}\left[\mathrm{K}^{+}\right]_{\mathrm{o}} \rightarrow$ reversal & $+++(>10 s)$ & - & - & - \\
\hline $\mathrm{AED} \rightarrow$ exocytosis & $++^{\mathrm{b}}(<8 \mathrm{~s})$ & $+^{\mathrm{b}}(<5 \mathrm{~s})$ & $+++(<1 \mathrm{~s})$ & $+++(<1 \mathrm{~s})$ \\
\hline
\end{tabular}

paper, only $7 S$, but not $d 4-500 \mathrm{r}$ cells, responded by ciliary reversal. However, both strains exhibited ciliary reversal, though with different intensity, during synchronous exocytosis induction by AED. In a series of microkinematographic images, the duration of a ciliary beat cycle was determined as $49 \mathrm{~ms}(\sim 20 \mathrm{~Hz}$, data not shown $)$.

\subsection{Fluorochrome analysis of $\left[\mathrm{Ca}^{2+}\right]$ signals in cilia during exocytosis stimulation}

The increase of $\left[\mathrm{Ca}^{2+}\right]$ in cilia during depolarisation has been amply documented by electrophysiology (see "Section 1"). No more details are available for calcium dynamics in cilia of Paramecium. We now analysed different types of stimulation and we also envisaged spill-over phenomena. We loaded $7 S$ and $d 4-500 r$ cells with Fluo-3 for rapid recording of $f / f_{\mathrm{o}}$ signals in a CLSM equipped with an opto-acustic beam deflection system (Fig. 1). In parallel, we performed EDX analyses.

According to previous work with $7 S$ cells, AED-stimulated synchronous trichocyst exocytosis causes a swift rise of the cortical $\mathrm{Ca}^{2+}$ signal in the stimulation area to over five times basal levels within $\sim 1 \mathrm{~s}[14,24]$. We now show that this is paralleled by a similar $\left[\mathrm{Ca}^{2+}\right]$ increase in cilia. In the typical example presented in Fig. 1A, AED stimulation is tightly followed, or superimposed by a slightly lower signal recorded in the adjacent layer of cilia in a $5 \mu \mathrm{m}$ broad frame adjacent to the cell boundary. Although the volume contributed by cilia in such a layer is much smaller than the adjacent cortical cytoplasmic layer, the $f / f_{\mathrm{o}}$ evaluation applied allows one to register true changes of $\left[\mathrm{Ca}^{2+}\right]$. In sum, we find a considerable $\left[\mathrm{Ca}^{2+}\right]$ increase in cilia during exocytosis stimulation. Since ciliary $\mathrm{Ca}^{2+}$-channels are irrelevant for exocytosis [22], this increase must be due to spill-over from the cytosol.

A similar analysis with $d 4-500 r$ cells gives quite similar results. A typical example is presented in Fig. 1B. The insert shows that, after AED application, $\left[\mathrm{Ca}^{2+}\right]$ in cilia again rises very rapidly from $20 \mathrm{~ms}$ on, i.e. within one ciliary stroke. As to be expected [22], this was paralleled by local trichocyst exocytosis at the stimulation site (not shown), just like in $7 \mathrm{~S}$ cells.

Table 2 summarises cortical $f l f_{\mathrm{o}}$ signals thus achieved. Clearly, $\mathrm{Ca}^{2+}$ sweeps into the ciliary basis very rapidly. As reported, during synchronous exocytosis induction $\mathrm{Ca}^{2+}$ signals can be recorded by a fast CLSM analysis within such short time periods [24-26], whereby exocytosis is completed within $80 \mathrm{~ms}$ [40].

In sum, the new information contained in Fig. $1 \mathrm{~A}$ and $\mathrm{B}$ says that $\mathrm{Ca}^{2+}$ spill-over into cilia occurs within one ciliary stroke and that this $\left[\mathrm{Ca}^{2+}\right]$ increase in the basal part of cilia can induce ciliary reversal.
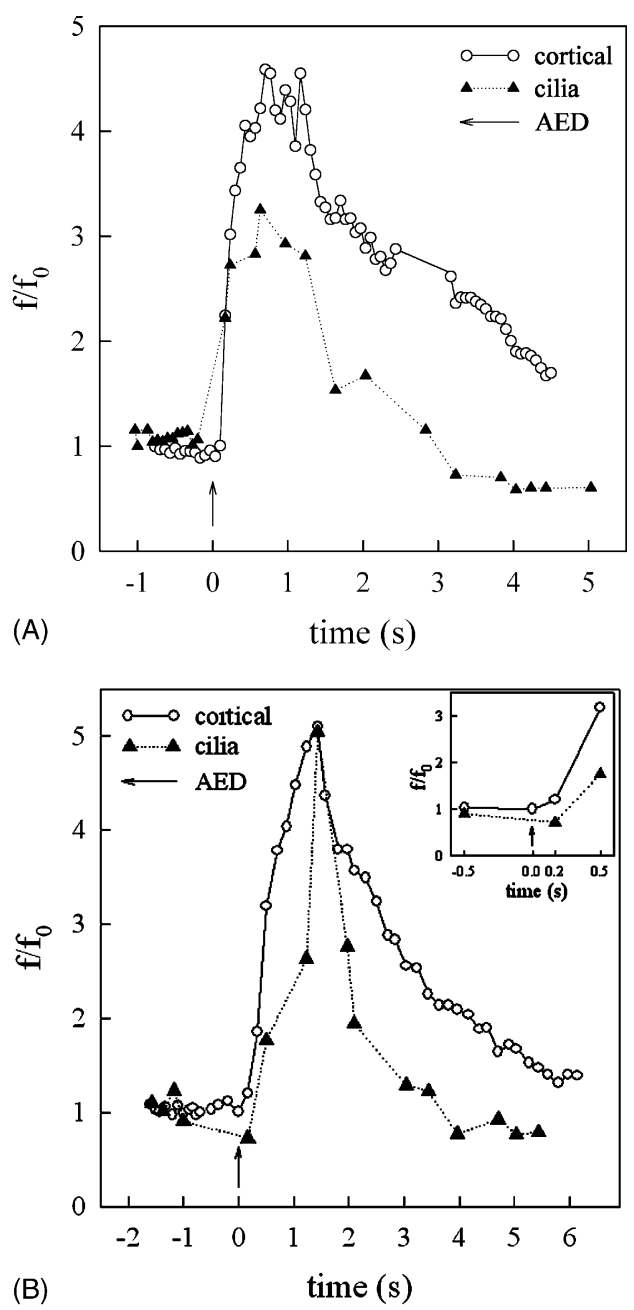

Fig. 1. AED-triggered exocytosis is accompanied by $\mathrm{Ca}^{2+}$ spill-over into cilia visible by fluorochrome analysis in $7 S$ (A) and in $d 4-500 r$ cells (B). Signals were recorded in the CLSM close to the site of AED application, not only in the outermost cell cortex, but also in a $\sim 5 \mu \mathrm{m}$ broad zone (containing beating cilia) adjacent to the cell surface. The time of AED application is marked by an arrow. 
Table 2

Kinetics of the AED-evoked $f / f_{\mathrm{o}} \mathrm{Ca}^{2+}$ signal in the cortex of $7 S$ and d4-500r cells ${ }^{\mathrm{a}}$

\begin{tabular}{lllll}
\hline Strain & $N$ & $\begin{array}{l}\text { Maximum } \\
f / f_{\mathrm{o}} \text { increase } \\
\pm \text { S.E.M. }\end{array}$ & $\begin{array}{l}t_{1 / 2} \text { signal rise } \\
(\mathrm{s}) \pm \text { S.E.M. }\end{array}$ & $\begin{array}{l}t_{1 / 2} \text { signal decay } \\
(\mathrm{s}) \pm \text { S.E.M. }\end{array}$ \\
\hline $7 S$ & 6 & $5.4 \pm 0.5$ & $0.26 \pm 0.03$ & $1.93 \pm 0.46$ \\
$d 4-500 r$ & 6 & $3.9 \pm 0.9$ & $0.75 \pm 0.18$ & $0.51 \pm 0.01$
\end{tabular}

${ }^{\mathrm{a}}\left[\mathrm{Ca}^{2+}\right]_{\mathrm{o}}=0.5 \mathrm{mM} . N=$ number of cells analysed.

\section{2. [Ca] recording by EDX in cilia during exocytosis stimulation}

When massive synchronous trichocyst exocytosis is stimulated by AED in $7 S$ cells spill-over of calcium into basal regions of cilia can also be seen in EDX analysis (Fig. 2). The positions of $\mathrm{Ca} \mathrm{K} \alpha$ recordings are marked in the STEM image, the block diagrams below show statistical evaluations from numerous such measurements. Position 3 indicates spot
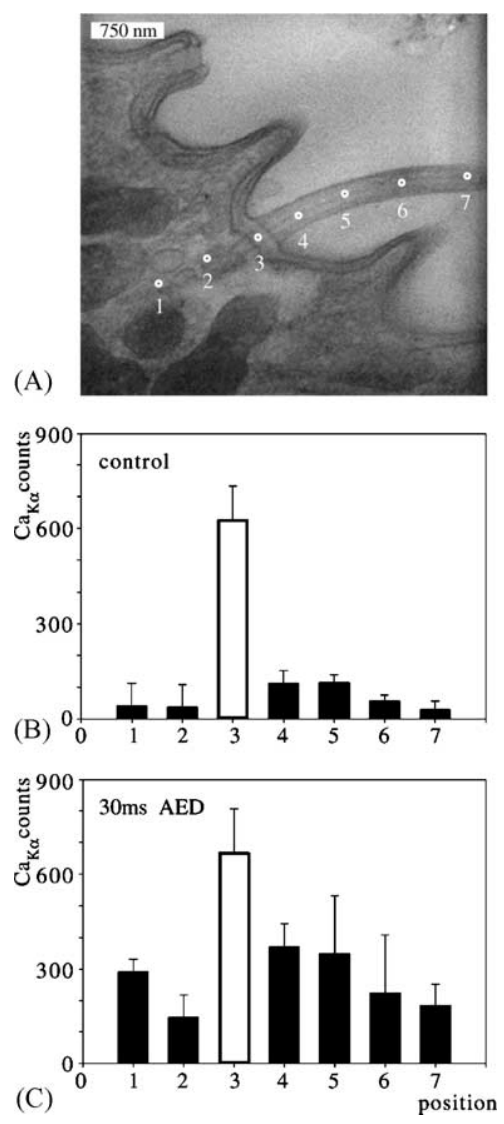

Fig. 2. AED-triggered exocytosis is accompanied by $\mathrm{Ca}^{2+}$ spill-over into cilia visible by EDX. Analyses with $7 S$ cells. (A) STEM image indicating positions where $\mathrm{Ca} \mathrm{K} \alpha$ signals have been recorded, (B) in mock-stimulated cells and $(\mathrm{C})$ in aliquots stimulated with AED $(30 \mathrm{~ms})$. Note that position " 3 " is located on the basal body with surrounding alveolar sacs which are contained and whose $\mathrm{Ca} \mathrm{K} \alpha$ signal is registered in the $0.5 \mu \mathrm{m}$ thick section analysed. S.E.M. $=$ standard error of the mean. Number of measurements (from positions 1 to 7), $n=12, N=12$, each in controls and stimulation experiments. measurements below the terminal plate in the domain where, in the $0.5 \mu \mathrm{m}$ thick section, alveolar sacs closely surround the basal body and may thus considerably contribute to the $\mathrm{Ca} \mathrm{K} \alpha$ signal. This is the only region from which the signal is identical before and after stimulation for the following reasons. Previous analyses have shown that $\mathrm{Ca}^{2+}$ release from alveolar sacs accompanying AED stimulation is counteracted within the first $80 \mathrm{~ms}$ by influx from the outside medium, before [Ca] decreases in alveolar sacs within a total of $1 \mathrm{~s}$ [39]. This explains why the $\mathrm{Ca} \mathrm{K} \alpha$ signal in alveolar sacs does not change during the brief AED stimulation (Fig. 2). However, as a consequence of brief AED stimulation, [Ca] rises dramatically in the cytosol, including the region below cilia. From there it rapidly sweeps into the ciliary shaft, with a remarkable decrease beyond the proximal $2 \mu \mathrm{m}$. Considering that a longitudinally cut cilium can occupy only half of a $0.5 \mu \mathrm{m}$ section, [Ca] values in cilia must reach a rather high value, i.e. comparable to that in alveolar sacs (determined as $43 \mathrm{mM}$ by Hardt and Plattner [38,39]). [Ca] values observed in cilia are also similar to those after depolarisation (see below) which can explain occurrence of ciliary reversal under conditions of AED stimulation.

In additional experiments, we have compared $\mathrm{Ca} \mathrm{K} \alpha$ values recorded in the cytosolic compartment, $0.5 \mu \mathrm{m}$ below ciliary basal bodies, and within cilia, $0.5 \mu \mathrm{m}$ above the terminal plate, after different times, between $30 \mathrm{~ms}$ and $1 \mathrm{~s}$ of AED stimulation of exocytosis (Fig. 3). For comparison, from previous analyses we know that synchronous exocytosis is completed within $80 \mathrm{~ms}$ [40], accompanied by considerable [Ca] changes close to exocytosis sites [39]. Can we see a time-dependent wave of calcium spill-over into cilia under such conditions?

This is probably the case in Fig. 3. While $\mathrm{Ca} \mathrm{K} \alpha$ signals in the cytosol and in the ciliary base are identical before AED stimulation (Fig. 3A), values rise to several times higher concentrations in the cytosol within $30 \mathrm{~ms}$ and then decay (Fig. 3B). This is paralleled by a smaller increase in the ciliary base at $30 \mathrm{~ms}$, followed by a slower decay. This strictly supports our previous conclusion derived from Figs. 1 and 2 that a wave of calcium enters cilia by spill-over during exocytosis stimulation.

\subsection{Effects of depolarisation on [Ca] in cilia of $7 \mathrm{~S}$ cells}

We used EDX to analyse [Ca] along the shaft of longitudinally cut cilia of $7 S$ cells (Table 3 ). To facilitate comparison of data which unexpectedly showed considerable fluctuations in recordings at different positions along the ciliary shaft, we pooled the $\mathrm{Ca} \mathrm{K} \alpha$ values recorded within a distance of $0.5-1.5 \mu \mathrm{m}$ from the ciliary basis and compared them with those from more remote domains. This way we tried to address the question whether $\mathrm{Ca}^{2+}$-influx channels may be evenly distributed or enriched in the ciliary base. (A distance of $0.5 \mu \mathrm{m}$ is sufficiently remote from alveolar sacs with their relatively high [Ca] [39].) It should be noted that it is very difficult to find cilia with a clear origin on a 
(A)
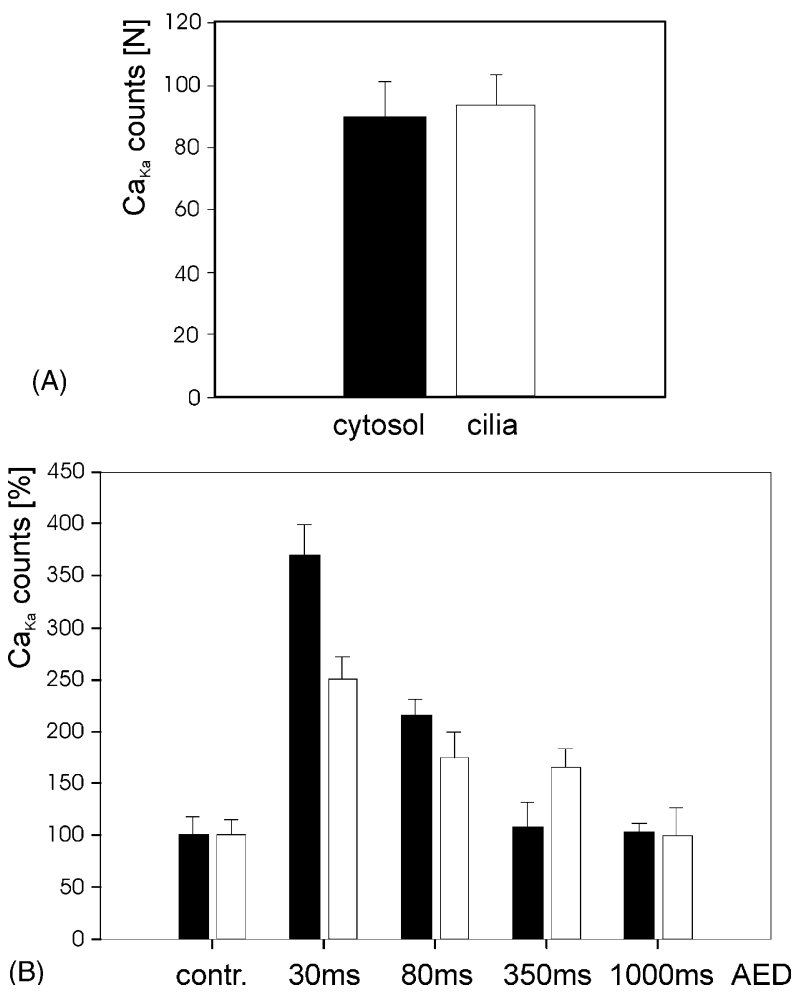

Fig. 3. Time-dependent spill-over of calcium into cilia in the course of exocytosis stimulation. (A) Absolute $\mathrm{Ca} \mathrm{K} \alpha$ counts in cytosol and cilia of unstimulated $7 S$ cells are about the same $0.5 \mu \mathrm{m}$ underneath and above the ciliary bases, respectively. $\left[\mathrm{Ca}^{2+}\right]_{\mathrm{e}}=500 \mu \mathrm{M}$; numbers for cytosol: $n=18, N=9$, for cilia: $n=16, N=9$. (B) Upon AED stimulation $[\mathrm{Ca}]$ in the cytosol (near exocytotic sites) increases within $30 \mathrm{~ms}$ to values $\sim 3.5$ times above basal levels, whereas [Ca] in the cilia (at position " $0.5 \mu \mathrm{m}$ ") increases by a factor of only 2.5 above rest; note also that [Ca] decays slower in the cilia as compared to the cytosol. Data points for cytosol: $n=51, N=9$ (control), $n=87, N=10$ (30 ms), $n=67$, $N=9(80 \mathrm{~ms}), n=28, N=7(350 \mathrm{~ms}), n=36, N=8(1 \mathrm{~s})$, for cilia: $n=18, N=9$ (control), $n=10, N=20$ (30 ms), $n=18, N=9$ (80 ms), $n=14, N=7$ (350 ms), $n=16, N=8(1 \mathrm{~s})$.

Table 3

$\mathrm{Ca} \mathrm{K} \alpha$ counts recorded along longitudinally cut cilia of $7 S$ cells, with or without $80-\mathrm{ms}$ depolarisation ${ }^{\mathrm{a}}$

\begin{tabular}{|c|c|c|}
\hline \multirow{2}{*}{$\begin{array}{l}\text { Experimental } \\
\text { conditions }\end{array}$} & \multicolumn{2}{|c|}{ Distance from ciliary basis } \\
\hline & 0-1.5 $\mu \mathrm{m} \pm$ S.E.M. & $>1.5-3.5 \mu \mathrm{m} \pm$ S.E.M. \\
\hline \multicolumn{3}{|c|}{ Without depolarisation } \\
\hline $\mathrm{Ca} \mathrm{K} \alpha$ counts & $\begin{array}{l}135 \pm 5 \\
n=74, N=47\end{array}$ & $\begin{array}{l}59 \pm 11 \\
n=17, N=15 \\
.001\end{array}$ \\
\hline \multicolumn{3}{|c|}{ With depolarisation } \\
\hline $\mathrm{Ca} \mathrm{K} \alpha$ counts & $\begin{array}{l}436 \pm 6 \\
n=19, N=13\end{array}$ & $\begin{array}{l}854 \pm 63 \\
n=14, N=12 \\
.001\end{array}$ \\
\hline
\end{tabular}

${ }^{\mathrm{a}}\left[\mathrm{Ca}^{2+}\right]_{\mathrm{o}}=1 \mathrm{mM} . n=$ number of cilia analysed, $N=$ number of cells analysed. cell body and an extension over several micrometres where, therefore, it is difficult to obtain recordings.

[Ca] values recorded in cilia from unstimulated $7 S$ cells decrease along the cilium, from $1.5 \mu \mathrm{m}$ on (Table 3 ). These cells were mock stimulated for $80 \mathrm{~ms}$, i.e. they passed through the quenched-flow apparatus in the medium in which they were contained (without increased $\left[\mathrm{K}^{+}\right]_{\mathrm{o}}$ ). In Table 3, aliquots were subjected to depolarisation for $80 \mathrm{~ms}$. In this case, [Ca] rose several times, particularly in more distal regions. A similar observation was made when cross-sectioned cilia around a cell, within still larger distances from the cell body, have been analysed (data not shown), though the precise origin or distance from a cell body could not be determined in that case.

In sum, from these data one may derive the conclusion that $\mathrm{Ca}^{2+}$-channels are not restricted to the ciliary base.

\subsection{No spill-over of calcium into the cytosolic compartment after depolarisation in $7 S$ cells}

Table 4 presents $\mathrm{Ca} \mathrm{K} \alpha$ readings recorded from different regions of $7 S$ cells, with or without 80-ms depolarisation. Table 4 also includes values recorded from alveolar sacs and from different cytosolic domains at a distance of $0.5 \mu \mathrm{m}$ from (longitudinally cut) basal bodies. Would depolarisation cause a calcium spill-over from cilia into the nearby cytosol? Consider that, at a distance of $0.5 \mu \mathrm{m}$ from the contact zone between docked trichocysts and alveolar sacs, we had previously recorded strong $\mathrm{Ca} \mathrm{K} \alpha$ signals during exocytosis stimulation [39].

In alveolar sacs, $\mathrm{Ca} \mathrm{K} \alpha$ values do not change after depolarisation (Table 4) -in agreement with the general assumption that under these conditions $\mathrm{Ca}^{2+}$ comes from the outside medium (see "Section 1"). The values have to be compared with $\mathrm{Ca} \mathrm{K} \alpha$ readings in alveolar sacs in previous

Table 4

$\mathrm{Ca} \mathrm{K} \alpha$ counts recorded in longitudinally cut cilia, alveolar sacs and cortical cytosol of $7 S$ cells

\begin{tabular}{|c|c|c|}
\hline & $\begin{array}{l}\text { Mock stimulation } \\
\pm \text { S.E.M. }\end{array}$ & $\begin{array}{l}\text { Stimulation (80-ms } \\
\text { depolarisation) } \pm \\
\text { S.E.M. }\end{array}$ \\
\hline \multirow{2}{*}{$\begin{array}{l}\text { Ca K } \alpha \text { counts in } \\
\text { cilia }^{\text {a }} \text { (mean) }\end{array}$} & $105 \pm 17$ & $495 \pm 77$ \\
\hline & \multicolumn{2}{|c|}{$P=0.001$} \\
\hline \multirow{2}{*}{$\begin{array}{l}\mathrm{Ca} \mathrm{K} \alpha \text { counts in } \\
\text { alveol sacs (mean) }\end{array}$} & $703 \pm 151$ & $903 \pm 127$ \\
\hline & \multicolumn{2}{|c|}{$P=0.444^{\mathrm{b}}$} \\
\hline \multirow{2}{*}{$\begin{array}{l}\text { Ca K } \alpha \text { counts in } \\
\text { cytosol }^{\mathrm{c}} \text { (mean) }\end{array}$} & $126 \pm 43$ & $67 \pm 11$ \\
\hline & \multicolumn{2}{|c|}{$P=0.645^{\mathrm{b}}$} \\
\hline
\end{tabular}

\footnotetext{
${ }^{a}$ All measurements from cilia pooled.

${ }^{b}$ No statistical change.

${ }^{\mathrm{c}}$ Measured within $0.5 \mu \mathrm{m}$ below ciliary bases.
} 
analyses [38,39] in which we have obtained a calibrated value of $[\mathrm{Ca}] \sim 43 \mathrm{mM}$. Ca $\mathrm{K} \alpha$ signals in cilia $80 \mathrm{~ms}$ after depolarisation must be a significant fraction of those recorded in alveolar sacs or even more (considering their small diameter in comparison to the $0.5 \mu \mathrm{m}$ section thickness). Table 4 also shows that no spill-over beyond the ciliary basis occurs. This agrees with the fact that depolarisation-induced ciliary reversal is not paralleled by trichocyst exocytosis (Table 1).

\subsection{Ciliary $[\mathrm{Ca}]$ in pawn cells}

According to pilot experiments, the situation is rather different in $d 4-500 r$ cells (data not shown). In the mock-stimulated cells, $\mathrm{Ca} \mathrm{K} \alpha$ readings are remarkably lower than in $7 S$ cells. Furthermore, 80-ms exposure to depolarisation conditions causes only little change. The latter had to be expected due to the absence of any $\mathrm{Ca}^{2+}$ influx under such conditions in the pawn strain (see "Section 1").

\section{Discussion}

$\mathrm{Ca}^{2+}$ regulates ciliary beat [8]. It is relevant for normal beat activity, not only in ciliated epithelia $[9,28,29]$ but also in Paramecium $[10,11,45]$. Beyond that, a $\left[\mathrm{Ca}^{2+}\right]$ increase can induce a ciliary or flagellar beat reversal in lower eukaryotes, like the green alga Chlamydomonas [46,47], ciliates (see reviews by Preston and Saimi [19], Plattner and Klauke [14]) and ctenophores $[48,49]$. In Paramecium, several molecular targets are envisaged [33,35,50], as discussed below, all with unknown distribution along the organelle.

\section{1. $\left[\mathrm{Ca}^{2+}\right]$ increase originating from depolarisation-dependent influx is the signal for ciliary reversal}

A multiplicity of signals can occur in cilia [19]. In Paramecium, the increase of intraciliary $\left[\mathrm{Ca}^{2+}\right]$ causing ciliary reversal $[17,20,23]$ is normally initiated by activation of mechano-sensitive $\mathrm{Ca}^{2+}$-channels in the non-ciliary cell membrane which entails depolarisation of the cell membrane potential [10-13,18-20]. This in turn opens voltage-dependent $\mathrm{Ca}^{2+}$-channels in the ciliary membrane [51,52]. The very same $\mathrm{Ca}^{2+}$ rapidly inactivates $\mathrm{Ca}^{2+}$-channels from the inside [53].

A rapid intraciliary $\left[\mathrm{Ca}^{2+}\right]$ increase is the relevant signal for induction of ciliary reversal, but how does this compare with other signals? All evidences favour $\mathrm{Ca}^{2+}$ as the relevant signal, whereas formation of cGMP during ciliary reversal in Paramecium $[50,54,55]$ may exert a modulatory effect only [45,56-60]. In Paramecium, guanylate cyclase is distributed over the ciliary membrane [61], but cGMP rises during ciliary reversal induction only with considerable delay $[56,62]$, at least $\sim 10$ times slower than $\left[\mathrm{Ca}^{2+}\right]$ [55]. Formation of cGMP is even considered the result of the $\left[\mathrm{Ca}^{2+}\right]$ increase $[63,64]$ occurring during ciliary reversal. Concomitantly,
$\mathrm{Ca}^{2+}$, which suffices as a signal in the permeabilised Paramecium model [23], is the relevant parameter to be analysed in the present context. In mammalian cells, cGMP serves only to modulate ciliary beat frequency $[28,65]$. Our present work adds further support to this concept since [Ca] in EDX increases in cilia within the duration of about one ciliary stroke, i.e. $\sim 10$ times faster than cGMP formation.

\subsection{Are voltage-dependent $\mathrm{Ca}^{2+}$-channels located exclusively in the ciliary cell membrane?}

Voltage-dependent $\mathrm{Ca}^{2+}$-influx channels are generally assumed to be restricted to the ciliary membrane since they disappear after deciliation and reappear during reformation of cilia [51,52]. However, Schultz et al. [66], based on their measurements of $\mathrm{Ca}^{2+}$-dependent cGMP increase after depolarisation of deciliated cells, came to the conclusion that they would be located, at least in part, also in the non-ciliary cell membrane. They assumed that such channels may still be present after deciliation, but in deactivated form, due to the different chemicals used to deciliate Paramecium cells.

In our EDX analyses with $7 S$ cells, we find, upon depolarisation, an increase of [Ca] within cilia, but not in cortical regions near basal bodies or anywhere below the non-ciliary cell membrane. This clearly favours a $\mathrm{Ca}^{2+}$ influx selectively through the ciliary membrane, particularly since, in principle, our methodology enables us to demonstrate also $\mathrm{a} \mathrm{Ca}^{2+}$ influx via the non-ciliary cell membrane, e.g. during exocytosis stimulation [39].

\subsection{Where in the ciliary membrane reside voltage-dependent $\mathrm{Ca}^{2+}$-channels?}

Since antibodies for immuno-localisation are not available this question could not be resolved so far and answers have remained speculative. In fact, conflicting evidence of an equal distribution along the cilium as well as of a basal enrichment has been presented. $\mathrm{Ca}^{2+}$ spill-over from the cell soma into cilia can induce ciliary beat reversal, as we show. Similarly, in ctenophores, ciliary bending can be initiated at the basis [49]. How does that compare with other systems and which relation exists to the distribution of $\mathrm{Ca}^{2+}$-channels and $\mathrm{Ca}^{2+}$-sensitive target molecules?

A variety of $\mathrm{Ca}^{2+}$-sensitive molecular targets occur in cilia of a Paramecium cell where they may participate in ciliary activity. This includes calmodulin [13,67], centrin-like proteins [33], possibly a protein kinase with calmodulin-like domains [68] and perhaps, as suggested from work with Chlamydomonas [47], a calmodulin-dependent protein kinase (which, however, is unknown so far from Paramecium). Their distribution along the ciliary shaft has not been analysed in detail as yet. Moreover, in Chlamydomonas, immuno-localisation of $\mathrm{p} 28$, a protein relevant for normal beat, sometimes appears distributed equally and sometimes enriched in basal regions of flagella [69]. 
In an attempt to learn more about the distribution of $\mathrm{Ca}^{2+}$-channels and $\mathrm{Ca}^{2+}$-sensitivity along flagella and cilia, more direct approaches have been made-all resulting in suggestions which we may be able to re-evaluate. Some authors analysed ciliary aggregates in ctenophores and some flagella in Chlamydomonas. In ctenophores, initiation of ciliary bending at the basis causes mechanical self-propagation of ciliary beat [48]. In mammals, $\left[\mathrm{Ca}^{2+}\right]$ in basal ciliary regions accounts for accelerated ciliary beat [9]. In Chlamydomonas, voltage-dependent $\mathrm{Ca}^{2+}$-conductance is lost after deflagellation, but increases to the same extent as flagella re-grow [46]. This was interpreted as localisation of $\mathrm{Ca}^{2+}$-channels throughout the flagellum. A similar observation was made after de-ciliation and subsequent re-ciliation in Paramecium [51]. However, channels could also be increasingly inserted at specific sites, like at the flagellar basis, as the organelle reforms. Another approach executed with Paramecium was subfractionation of ciliary membranes, loading with the $\mathrm{Ca}^{2+}$-fluorochrome arsenazo III and subsequent exposure to a depolarisation medium [50]. With the major vesicle subpopulations similar $\mathrm{Ca}^{2+}$ signals were recorded. Although this was again interpreted as indicating equal distribution of channels over the entire cilium, the problem of sidedness after resealing, of variable vesicle subpopulations and of "hybridisation" by fusion has not been addressed.

More direct approaches were as follows. Hamasaki and Naitoh [70] have applied $\mathrm{Ca}^{2+}$ by micropipettes very locally along cilia. They found that basal regions are more sensitive than more distal ones. More recently, Iwadate [37] found by laser activation of caged $\mathrm{Ca}^{2+}$ that the distal part of cilia also contains the $\mathrm{Ca}^{2+}$-sensitive machinery relevant for ciliary beat reversal.

Our present data provide independent support of the idea that voltage-dependent $\mathrm{Ca}^{2+}$-influx channels may be positioned not only in basal regions of cilia, although a $\left[\mathrm{Ca}^{2+}\right]$ increase in the ciliary basis can suffice to induce ciliary reversal. The first argument is supported by the observation that, upon depolarisation, $[\mathrm{Ca}$ ] does not selectively rise in the basal regions. The second aspect is supported by the occurrence of ciliary reversal in pawn mutants, when exocytosis stimulation provokes a $\mathrm{Ca}^{2+}$ spill-over from the cell body into the basis of cilia, while normally these cells are not capable of ciliary reversal.

\subsection{The ciliary $\mathrm{Ca}^{2+}$ signal does not sweep into exocytotic microdomains}

Depolarisation does not cause exocytosis of trichocysts [21] and ciliary voltage-dependent $\mathrm{Ca}^{2+}$-channels are irrelevant for this process [22]. Accordingly, in our current EDX analyses calcium is not seen to sweep into exocytosis sites and not even to beyond the base of a cilium. This may be due to several effects, (i) the rapid deactivation of voltage-dependent $\mathrm{Ca}^{2+}$-channels by the very same $\mathrm{Ca}^{2+}$ which enters the cilium [53], (ii) the rapid binding of $\mathrm{Ca}^{2+}$ by the numerous $\mathrm{Ca}^{2+}$-binding target molecules (see above). These must provide a high $\mathrm{Ca}^{2+}$ buffer capacity, considering the magnitude of the $\mathrm{Ca} \mathrm{K} \alpha$ signal.

\subsection{Spill-over of $\mathrm{Ca}^{2+}$ from activated exocytosis sites into cilia}

During stimulated synchronous trichocyst exocytosis $\mathrm{Ca}^{2+}$ mobilisation from alveolar sacs is superimposed by a "store-operated $\mathrm{Ca}^{2+}$ influx", SOC, through the non-ciliary cell membrane [26,27]. SOC is triggered by the emptying of the cortical stores with which it has to act in concert. In sum, a local $\left[\mathrm{Ca}^{2+}\right]$ signal of $\sim 5 \mu \mathrm{M}$ is required for full exocytotic response [14,24,71]. Evidently this enormous $\mathrm{Ca}^{2+}$ flux arising from influx over the extensive non-ciliary cell membrane and from $\mathrm{Ca}^{2+}$ release from the extensive cortical stores is strong enough to sweep into the basis of cilia and to cause ciliary reversal, as we show. In contrast, the opposite phenomenon, i.e. spill-over from cilia into the cytosol, does not work, probably because of the rapid inactivation of ciliary $\mathrm{Ca}^{2+}$-channels and of a high $\mathrm{Ca}^{2+}$ buffer capacity.

\subsection{Comparison with electrophysiological data and balance calculations}

According to Table 4, Ca K $\alpha$ counts in cilia rise approximately five times after depolarisation. Since longitudinally cut cilia occupy only $\sim 50 \%$ of the section thickness used, comparison of the $\mathrm{Ca} \mathrm{K} \alpha$ values registered in cilia after depolarisation with those in alveolar sacs (where it remains unchanged during stimulation) indicate a comparable [Ca] in these organelles. Recall that in alveolar sacs [Ca] is $\sim 43 \mathrm{mM}$ [38,39]. Are our data compatible with estimations by other methods?

Based on voltage clamp analyses, an estimation of $\mathrm{Ca}^{2+}$ molecules which cross the ciliary membrane under optimal conditions can be attempted. A pilot calculation shows that this could yield a maximal [Ca] within cilia of the order of $\sim 50 \mathrm{mM}$ (R.R. Preston, personal communication) which is easily detectable by EDX [38]. Assuming that in cilia $\sim 99.9 \%$ of $\mathrm{Ca}^{2+}$ are rapidly bound [72] both our data sets, those of $[\mathrm{Ca}]$ and $\left[\mathrm{Ca}^{2+}\right]$ combined, would result a residual free $\mathrm{Ca}^{2+}$ concentration of $50 \mu \mathrm{M}$, i.e. $\sim 700$ free $\mathrm{Ca}^{2+}$ atoms in a cilium after activation. A broader range of estimation, from $10 \mu \mathrm{M}$ to $1 \mathrm{mM}$, has also been reported $[73,74]$. All these values exceed the reported activation by $1 \mu \mathrm{M}$ in vitro [23] when permeabilisation may cause CaBP extraction or other phenomena which may entail a lower activation threshold.

Would our estimation, $\left[\mathrm{Ca}^{2+}\right] \sim 50 \mu \mathrm{M}$ in activated cilia, be sufficient for detection by fluorochromes? Our $f / f_{\mathrm{o}}$ ratio evaluation does not allow to directly compare readings in cilia and in the nearby cortical domains. Though the fluorochrome signal in cilia during reversal is smaller than that in the nearby cell cortex, relative values recorded in cilia 
must considerably exceed the signal recorded in the nearby cell cortex - otherwise it would be undetectable according to our experience. A fraction of only $1.4 \%$ would be expected if $\left[\mathrm{Ca}^{2+}\right]$ were equal in cilia and cell cortex since cilia (more precisely, their basal regions) contained in the extracellular layer occupy only $\sim 1.4 \%$ of the volume available (one cilium per kinetid unit area of $3.45 \mu \mathrm{m}^{2}$ [25]). Since ciliary signals are well detectable the high magnitude of $\left[\mathrm{Ca}^{2+}\right]$ estimated above for cilia after depolarisation appears realistic. If so, calcium homeostasis must be re-established after depolarisation by a high buffer capacity, considering the absence of diffusion into the cell cortex (this paper) and the reported absence of a $\mathrm{Ca}^{2+}$-pump (ATPase) from ciliary membranes in Paramecium [75].

\subsection{Functional aspects of ciliary reversal}

Ciliary reversal serves the avoidance reaction when a Paramecium cell hits an obstacle. In a more complicated situation, when a Paramecium cell meets a predatory organism, the first reaction is expulsion of elongate trichocysts to keep the predator at a distance, as first shown by Harumoto and Miyake [76] and in more detail by Knoll et al. [44]. The concept of a defensive function of trichocyst expulsion [76] can be supplemented by the observation that this is followed with little delay by ciliary reversal [44]. The effect can be seen, e.g. in Fig. 3 of Ref. [44], where a $7 S$ cell, after releasing trichocysts upon contact with a Dileptus cell, withdraws by $\sim 40 \mu \mathrm{m}$ (cell width) within $12 \mathrm{~ms}$ - too short a time to be captured. The present work shows the possible basis of a tandem signalling involved in these two successive reactions.

\section{Acknowledgements}

We gratefully acknowledge financial support by grants from the Deutsche Forschungsgemeinschaft to H.P.

\section{References}

[1] M.J. Berridge, M.D. Bootman, P. Lipp, Calcium-a life and death signal, Nature 395 (1998) 645-648.

[2] M.J. Berridge, P. Lipp, M.D. Bootman, The versatility and universality of calcium signalling, Nat. Rev. Mol. Cell. Biol. 1 (2000) 11-21.

[3] M.J. Berridge, M.D. Bootman, H.L. Roderick, Calcium signalling: dynamics, Nat. Rev. Mol. Cell. Biol. 4 (2003) 517-529.

[4] G.J. Barritt, Receptor-activated $\mathrm{Ca}^{2+}$ influx in animal cells: a variety of pathways tailored to meet different intracellular $\mathrm{Ca}^{2+}$ signalling requirements, Biochem. J. 337 (1999) 153-169.

[5] E. Carafoli, J. Krebs (Eds.), Calcium Homeostasis, Springer-Verlag, Berlin, Heidelberg, New York, 2000, p. 188.

[6] A. Korngreen, Z. Priel, Simultaneous measurement of ciliary beating and intracellular calcium, Biophys. J. 67 (1994) 377-380.

[7] W. Dentler, G. Witman, Cilia and Flagella, Academic Press, San Diego, New York, London, 1995, p. 603.

[8] M. Salathe, R.J. Bookman, Coupling of $\left[\mathrm{Ca}^{2+}\right]_{\mathrm{i}}$ and ciliary beating in cultured tracheal epithelial cells, J. Cell Sci. 108 (1995) 431-440.
[9] A.B. Lansley, M.J. Sanderson, Regulation of airway ciliary activity by $\mathrm{Ca}^{2+}$ : simultaneous measurement of beat frequency and intracellular $\mathrm{Ca}^{2+}$, Biophys. J. 77 (1999) 629-638.

[10] H. Machemer, Electrophysiology, in: H.-D. Görtz (Ed.), Paramecium, Springer-Verlag, Berlin, Heidelberg, New York, 1988, pp. 185215.

[11] H. Machemer, Motor control of cilia, in: H.-D. Görtz (Ed.), Paramecium, Springer-Verlag, Berlin, Heidelberg, New York, 1988, pp. 216-235.

[12] J. Pernberg, H. Machemer, Fluorometric measurement of the intracellular free $\mathrm{Ca}^{2+}$-concentration in the ciliate Didinium nasutum using Fura-2, Cell Calcium 18 (1995) 484-494.

[13] H. Machemer, P.F.M. Teunis, Sensory-motor coupling and motor responses, in: K. Hausmann, P.C. Bradbury (Eds.), Ciliates. Cells and Organisms, Gustav Fischer Verlag, Stuttgart, 1996, pp. 379402.

[14] H. Plattner, N. Klauke, Calcium in ciliated protozoa: sources, regulation, and calcium regulated cell functions, Int. Rev. Cytol. 201 (2001) 115-208.

[15] R.D. Allen, Cytology, in: H.-D. Görtz (Ed.), Paramecium, Springer Verlag, Berlin, Heidelberg, New York, 1998, pp. 4-40.

[16] H. Plattner, My favorite cell—Paramecium, BioEssays 24 (2002) 649-658.

[17] Y. Naitoh, R. Eckert, Ionic mechanisms controlling behavioral responses of Paramecium to mechanical stimulation, Science 164 (1969) 963-965.

[18] H. Machemer, Interactions of membrane potential and cations in regulation of ciliary activity in Paramecium, J. Exp. Biol. 65 (1976) 427-448.

[19] R.R. Preston, Y. Saimi, Calcium ions and the regulation of motility, in: R.A. Bloodgood (Ed.), Ciliary and Flagellar Membranes, Plenum Press, New York, London, 1990, pp. 173-200.

[20] Y. Naitoh, Reactivation of extracted Paramecium models, Methods Cell Biol. 47 (1995) 211-224.

[21] C. Erxleben, H. Plattner, $\mathrm{Ca}^{2+}$ release from subplasmalemmal stores as a primary event during exocytosis in Paramecium cells, J. Cell Biol. 127 (1994) 935-945.

[22] H. Plattner, H. Matt, H. Kersken, B. Haacke, R. Stürzl, Synchronous exocytosis in Paramecium cells. I. A novel approach, Exp. Cell Res. 151 (1984) 6-13.

[23] Y. Naitoh, H. Kaneko, Reactivated triton-extracted models of Paramecium: modification of ciliary movement by calcium ions, Science 176 (1972) 523-524.

[24] N. Klauke, H. Plattner, Imaging of $\mathrm{Ca}^{2+}$ transients induced in Paramecium cells by a polyamine secretagogue, J. Cell Sci. 110 (1997) 975-983.

[25] C. Erxleben, N. Klauke, M. Flötenmeyer, M.-P. Blanchard, C. Braun, H. Plattner, Microdomain $\mathrm{Ca}^{2+}$ activation during exocytosis in Paramecium cells. Superposition of local subplasmalemmal calcium store activation by local $\mathrm{Ca}^{2+}$ influx, J. Cell Biol. 136 (1997) 597-607.

[26] N. Klauke, M.-P. Blanchard, H. Plattner, Polyamine triggering of exocytosis in Paramecium involves an extracellular $\mathrm{Ca}^{2+} /$ (polyvalent cation)-sensing receptor, subplasmalemmal Ca-store mobilization and store-operated $\mathrm{Ca}^{2+}$ influx via unspecific cation channels, J. Membr. Biol. 174 (2000) 141-156.

[27] I. Mohamed, N. Klauke, J. Hentschel, J. Cohen, H. Plattner, Functional and fluorochrome analysis of an exocytotic mutant yields evidence of store-operated $\mathrm{Ca}^{2+}$ influx in Paramecium, J. Membr. Biol. 187 (2002) 1-14.

[28] M. Salathe, R.J. Bookman, Mode of $\mathrm{Ca}^{2+}$ action on ciliary beat frequency in single ovine airway epithelial cells, J. Physiol. 520 (1999) 851-865.

[29] J.H. Evans, M.J. Sanderson, Intracellular calcium oscillations regulate ciliary beat frequency of airway epithelial cells, Cell Calcium 26 (1999) 103-110. 
[30] K.S. Kits, T.A. DeVlieger, B.W. Kooi, H.D. Mansvelder, Diffusion barriers limit the effect of mobile calcium buffers on exocytosis of large dense cored vesicles, Biophys. J. 76 (1999) 1693-1705.

[31] R.H. Chow, J. Klingauf, C. Heinemann, R.S. Zucker, E. Neher, Mechanisms determining the time course of secretion in neuroendocrine cells, Neuron 16 (1996) 369-376.

[32] F.D. Marengo, J.R. Monck, Development and dissipation of $\mathrm{Ca}^{2+}$ gradients in adrenal chromaffin cells, Biophys. J. 79 (2000) 18001820.

[33] K. Kim, M. Son, J.B. Peterson, D.L. Nelson, $\mathrm{Ca}^{2+}$-binding proteins of cilia and infraciliary lattice of Paramecium tetraurelia: their phosphorylation by purified endogenous $\mathrm{Ca}^{2+}$-dependent protein kinases, J. Cell Sci. 115 (2002) 1973-1984.

[34] D.M. Casey, T. Yagi, R. Kamiya, G.B. Witman, DC3, the smallest subunit of the Chlamydomonas flagellar outer dynein arm-docking complex, is a redox-sensitive calcium-binding protein, J. Biol. Chem. 278 (2003) 42652-42659.

[35] M. Noguchi, J.-Y. Sasaki, H. Kamachi, H. Inoue, Protein phosphatase $2 \mathrm{C}$ is involved in the cAMP-dependent ciliary control in Paramecium caudatum, Cell Motil. Cytoskel. 54 (2003) 95-104.

[36] E. Neher, Vesicle pools and $\mathrm{Ca}^{2+}$ microdomains: new tools for understanding their roles in neurotransmitter release, Neuron 20 (1998) 389-399.

[37] Y. Iwadate, Photolysis of caged calcium in cilia induces ciliary reversal in Paramecium caudatum, J. Exp. Biol. 206 (2003) 11631170.

[38] M. Hardt, H. Plattner, Quantitative energy-dispersive X-ray microanalysis of calcium dynamics in cell suspensions during stimulation on a sub-second time scale: preparative and analytical aspects as exemplified by Paramecium cells, J. Struct. Biol. 128 (1999) 187-199.

[39] M. Hardt, H. Plattner, Sub-second quenched-flow/X-ray microanalysis shows rapid $\mathrm{Ca}^{2+}$ mobilization from cortical stores paralleled by $\mathrm{Ca}^{2+}$ influx during synchronous exocytosis in Paramecium cells, Eur. J. Cell Biol. 79 (2000) 642-652.

[40] G. Knoll, C. Braun, H. Plattner, Quenched flow analysis of exocytosis in Paramecium cells: time course, changes in membrane structure, and calcium requirements revealed after rapid mixing and rapid freezing of intact cells, J. Cell Biol. 113 (1991) 1295-1304.

[41] G. Knoll, A. Grässle, C. Braun, W. Probst, B. Höhne-Zell, H. Plattner, A calcium influx is neither strictly associated with nor necessary for exocytotic membrane fusion in Paramecium cells, Cell Calcium 14 (1993) 173-183.

[42] M. Poenie, D. Epel, Ultrastructural localization of intracellular calcium stores by a new cytochemical method, J. Histochem. Cytochem. 35 (1987) 939-956.

[43] N. Haga, M. Forte, Y. Saimi, C. Kung, Microinjection of cytoplasm as a test of complementation in Paramecium, J. Cell Biol. 92 (1982) 559-564.

[44] G. Knoll, B. Haacke-Bell, H. Plattner, Local trichocyst exocytosis provides an efficient escape mechanism for Paramecium cells, Eur. J. Protistol. 27 (1991) 381-385.

[45] Y. Nakaoka, H. Machemer, Effects of cyclic nucleotides and intracellular $\mathrm{Ca}$ on voltage-activated ciliary beating in Paramecium, J. Comp. Physiol. A 166 (1990) 401-406.

[46] C. Beck, R. Uhl, On the localization of voltage-sensitive calcium channels in the flagella of Chlamydomonas reinhardtii, J. Cell Biol. 125 (1994) 1119-1125.

[47] E.F. Smith, Regulation of flagellar dynein by calcium and a role for an axonemal calmodulin and calmodulin-dependent kinase, Mol. Biol. Cell 13 (2002) 3303-3312.

[48] S. Tamm, $\mathrm{Ca}^{2+}$ channels and signalling in cilia and flagella, Trends Cell Biol. 4 (1994) 305-310.

[49] S.L. Tamm, M. Terasaki, Visualization of calcium transients controlling orientation of ciliary beat, J. Cell Biol. 125 (1994) 1127-1135.

[50] J.S. Thiele, S. Klumpp, J.E. Schultz, C.F. Bardele, Differential distribution of voltage-dependent calcium channels and guanylate cyclase in the excitable ciliary membrane from Paramecium tetraurelia, Eur. J. Cell Biol. 28 (1982) 3-11.

[51] H. Machemer, A. Ogura, Ionic conductances of membranes in ciliated and deciliated Paramecium, J. Physiol. 296 (1979) 49-60.

[52] A. Ogura, H. Machemer, Distribution of mechanoreceptor channels in the Paramecium surface membrane, J. Comp. Physiol. A 135 (1980) 233-242.

[53] P. Brehm, R. Eckert, Calcium entry leads to inactivation of calcium channel in Paramecium, Science 202 (1978) 1203-1206.

[54] J. Thiele, J.E. Schultz, Ciliary membrane vesicles of paramecium contain the voltage-sensitive calcium channel, Proc. Natl. Acad. Sci. U.S.A. 78 (1981) 3688-3691.

[55] W.Q. Yang, C. Braun, H. Plattner, J. Purvee, J.L. Van Houten, Cyclic nucleotides in glutamate chemosensory signal transduction of Paramecium, J. Cell Sci. 110 (1997) 2567-2572.

[56] T. Majima, T. Hamasaki, T. Arai, Increase in cellular cyclic GMP level by potassium stimulation and its relation to ciliary orientation in Paramecium tetraurelia, Experientia 42 (1985) 62-64.

[57] M. Noguchi, Y. Nakamura, K. Okamoto, Control of ciliary orientation in ciliated sheets from Paramecium-differential distribution of sensitivity to cyclic nucleotides, Cell Motil. Cytoskelet. 20 (1991) $38-46$.

[58] J. Bernal, B.E. Ehrlich, Guanine nucleotides modulate calcium currents in a marine Paramecium, J. Exp. Biol. 176 (1993) 117-133.

[59] K.I. Okamoto, Y. Nakaoka, Reconstitution of metachronal waves in ciliated cortical sheets of Paramecium. I. Wave stabilities, J. Exp. Biol. 192 (1994) 61-72.

[60] L.L. Pech, Regulation of ciliary motility in Paramecium by cAMP and cGMP, Comp. Biochem. Physiol. 111A (1995) 31-37.

[61] J.U. Linder, P. Engel, A. Reimer, T. Krüger, H. Plattner, A. Schultz, J.E. Schultz, Guanylyl cyclases with the topology of mammalian adenylyl cyclases and an N-terminal P-type ATPase-like domain in Paramecium, EMBO J. 18 (1999) 4222-4232.

[62] G. Knoll, D. Kerboeuf, H. Plattner, A rapid calcium influx during exocytosis in Paramecium cells is followed by a rise in cyclic GMP within 1 s, FEBS Lett. 304 (1992) 265-268.

[63] J.E. Schultz, T. Pohl, S. Klumpp, Voltage-gated $\mathrm{Ca}^{2+}$ entry into Paramecium linked to intraciliary increase of cyclic GMP, Nature 322 (1986) 271-273.

[64] J.E. Schultz, S. Klumpp, Cyclic nucleotides and calcium signaling in Paramecium, Adv. Cycl. Nucl. Phosphoprotein Res. 27 (1993) $25-46$.

[65] N. Uzlaner, Z. Priel, Interplay between the NO pathway and elevated $\left[\mathrm{Ca}^{2+}\right]_{\mathrm{i}}$ enhances ciliary activity in rabbit trachea, J. Physiol. 516 (1999) 179-190.

[66] J.E. Schultz, Y.L. Guo, G. Kleefeld, H. Völkel, Hyperpolarizationand depolarisation-activated $\mathrm{Ca}^{2+}$ currents in Paramecium trigger behavioral changes and cGMP formation independently, J. Membr. Biol. 156 (1997) 251-259.

[67] M. Momayezi, H. Kersken, U. Gras, J. Vilmart-Seuwen, H. Plattner, Calmodulin in Paramecium tetraurelia: localization from the in vivo to the ultrastructural level, J. Histochem. Cytochem. 34 (1986) 16211638 .

[68] K. Kim, L.A. Messinger, D.L. Nelson, $\mathrm{Ca}^{2+}$-dependent protein kinases of Paramecium: cloning provides evidence of a multigene family, Eur. J. Biochem. 251 (1998) 605-612.

[69] M. Hayashi, H.-A. Yanagisawa, M. Hirono, R. Kamiya, Rescue of a Chlamydomonas inner-arm-dynein-deficient mutant by electroporation-mediated delivery of recombinant p28 light chain, Cell Motil. Cytoskel. 53 (2002) 273-280.

[70] T. Hamasaki, Y. Naitoh, Localization of calcium-sensitive reversal mechanism in a cilium of Paramecium, Proc. Jpn. Acad. 61B (1985) $140-143$.

[71] H. Plattner, C. Braun, J. Hentschel, Facilitation of membrane fusion during exocytosis and exocytosis-coupled endocytosis and acceleration of "ghost" detachment in Paramecium by extracellular calcium. 
A quenched-flow/freeze-fracture analysis, J. Membr. Biol. 158 (1997) 197-208.

[72] H. Mogami, J. Gardner, O.V. Gerasimenko, P. Camello, O.H. Petersen, A.V. Tepikin, Calcium binding capacity of the cytosol and endoplasmic reticulum of mouse pancreatic acinar cells, J. Physiol. 518 (1999) 463-467.

[73] R. Eckert, Bioelectric control of ciliary activity, Science 176 (1972) 473-481.
[74] D. Oertel, S.J. Schein, C. Kung, Separation of membrane currents using a Paramecium mutant, Nature 268 (1977) 120 124.

[75] J. Van Houten, Chemosensory transduction in Paramecium, Eur. J. Protistol. 34 (1998) 301-307.

[76] T. Harumoto, A. Miyake, Defensive function of trichocysts in Paramecium, J. Exp. Zool. 260 (1991) 84-92. 